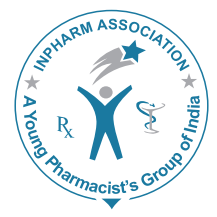

\title{
Foreign pharmacy graduate equivalent examination certification: Passport to the promised land for Indian Pharm.D graduates
}

\author{
Anoop Paruchuri ${ }^{1,2}$, Akram Ahmad ${ }^{1,3 *}$ \\ ${ }^{1}$ Department of Pharmacy Practice, Annamalai University, Chidambaram, Cuddalore, Tamil Nadu, India, \\ ${ }^{2}$ Intern at American Speciality Pharmacy, Plano, Texas - 75454, USA, ${ }^{3}$ Department of Clinical Pharmacy, \\ ${ }^{3}$ Faculty of Pharmaceutical Sciences, UCSI University, No. 1 Jalan Menara Gading, UCSI Heights, \\ Cheras - 56000, Kuala Lumpur, Malaysia
}

\begin{abstract}
It's any pharmacy students dream to practice their profession in the United States (US) because it stands out in providing dignity and the remuneration it pays off to the pharmacist than any other country in the world. Foreign pharmacy graduate equivalent examination (FPGEE) certification is mandated to all the foreign pharmacists as a first step to practice pharmacy profession in the United States of America. After the new requirement mandated in the US from 2003, Pharmacy Council of India launched doctor of pharmacy as a 6 years integrated course to help the college ready students and a 3 year post-baccalaureate bridge course for the students graduated after 2003 as an intervention in 2008. Even though the process is so laborious most of the foreign graduates think it's worth taking a shot. It starts off with applying for transcripts and ends with taking up the FPGEE held by the National Association of Board of Pharmacy (NABP). Obtaining eligibility for the exam is a laborious process that can take anywhere from 6 months to 1 year depending upon the university of graduation, country's pharmacy board/council, its reciprocation with the NABP and the country's postal transit. Despite fulfilling all the requirements accurately, the entry of the candidate into the country is not certain as it lies in the hands of the visa issuing offer whose actions are always unpredictable.
\end{abstract}

Key words: Doctor of Pharmacy Integrated, Doctor of Pharmacy Post Baccalaureate, Foreign Pharmacy Graduate Equivalent Examination, National Association of Board of Pharmacy, NAPLEX

\section{INTRODUCTION}

Apropos of working as a pharmacist in the United States (US), the students graduated before 2003 can be labeled

\begin{tabular}{|c|l|}
\hline \multicolumn{2}{|c|}{ Access this article online } \\
\hline \multirow{2}{*}{ Journal Sponsor } & \multicolumn{1}{|l|}{ Website: } \\
www.jyoungpharm.org \\
\hline \multirow{2}{*}{ www.phcognet } & $\begin{array}{l}\text { DOI: } \\
\text { Do.5530/jyp.2014.3.1 }\end{array}$ \\
\hline
\end{tabular}

"Favored" as no restrictions were imposed on the foreign graduates by the National Association of Board of Pharmacy (NABP). It was for the students graduated in or after 2003 who were subjected to limitation by the board mandating a 5 years graduate degree in pharmacy. With respect to India, the pharmacy graduate curriculum was only a 4 years course regulated by the Pharmacy Council of India (PCI). This ruled barred many of the student's graduated later than 2003 from perusing an employment in the US. Thanks to the PCI, a 3 years bridge program doctor of pharmacy (Pharm.D). Post Baccalaureate (Post. Bacc) for the post 2003 graduates, and a 6 years Pharm.D.

\footnotetext{
*Address for correspondence:

Dr. Akram Ahmad, Department of Clinical Pharmacy, Faculty of Pharmaceutical Sciences, UCSI University, No. 1 Jalan Menara Gading, UCSI Heights, Cheras - 56000, Kuala Lumpur, Malaysia.E-mail: akrampharma67@gmail.com
} 
Program (Integrated) for students who are college ready was launched in the year 2008 in couple of states and all over India by 2010. ${ }^{2,3}$ This intervention quite opened the doors for the 6 years Pharm.D students, questioning the eligibility status of Post. Bacc students. As per the NABP's rules, a candidate with a 5 years or more pharmacy undergraduate degree is by default mediated eligible for the foreign pharmacy graduate equivalent examination (FPGEE), whereas a Post. Bacc candidate will be subjected to case by case evaluation prior to being rendered eligible. ${ }^{4}$ Once the candidate is deemed eligible to sit for FPGEE by the board the rest is assured eligible all the way till NAPLEX and MPJE.

\section{$\mathrm{NABP}^{4}$}

Over 95\% student's perusing a pharmacy career must have come across the term FPGEE at least once during their education. It is an entry level examination conducted by the NABP for all the foreign pharmacists who are determined eligible by the board. NABP is akin to PCI. It was established in 1904, to ensure the public's health and safety through its pharmacist license transfer and pharmacist competence assessment programs. Apart from the 50 states in the US it also governs the District of Columbia, Guam, Puerto Rico, the Virgin Islands, Australia, eight Canadian provinces, and New Zealand.

\section{Composition}

The association is governed by the three officers, eight members, and chairperson who comprise the Executive Committee volunteer their time and expertise to implement policy and oversee the Association's programs and activities. Officers and members are elected by the Association's membership during the NABP Annual Meeting. The executive director serves as the secretary of the Executive Committee and is appointed by the Executive Committee. ${ }^{4}$

\section{The exam}

The FPGEE, is one of the examinations required as part of the FPGEC Certification Program. It is an online, almost 6 h, administered by Pearson VUE at its Pearson Professional Centers in the continental US. The exam contains 250 questions where the questions are divided as per the following:

- Basic biomedical sciences - $16 \%$

- Pharmaceutical sciences - 30\%

- Social, behavioral, administrative pharmacy sciences $22 \%$

- Clinical sciences $-32 \%$
This examination is offered only twice a year the first being in the last week of April and the second time during the last week of September. The dates are scheduled by the NABP and are subjected to change every year. ${ }^{4}$

\section{Documents required}

The application process is the most paramount process as it determines the test is taking eligibility for the candidate. Failure of the candidate to comply with the standards and requirements of the board may result in denial of the application and lifetime ban being from taking the test being the worst case scenario. Hence out most attention should be paid while submitting the application and its supporting documents to the board. The following is a stepwise application process.

\section{Application}

The application can be downloaded or filled and submitted online using adobe from the board's website http://www. nabp.net/programs/examination/fpgec/application-bulletin. There is a filled sample application which acts as reference and step wise information needed for every individual part of the application. Attention should be focused while filling the last part of the application as it requires a notary by the concerned professional. A fee of $1200 \$$ is to be along with the application in the accepted form of payment. ${ }^{5}$

\section{Transcripts}

The transcripts should be issued by the Registrar/Controller of Examination of the candidate's respective university in a sealed cover dated and signed by the registrar or any other issuing authority. The signed transcripts should then be enveloped, sealed and should bear the stamp/seal with the signature of the issuing authority. Opened transcripts or sealed transcripts without bearing the sign/sign are considered invalid by the board. The transcripts usually include 4 years mark lists and original degree (provisional if original degree is not received at the time of application) for post back students and 6 years mark list and original degree for integrated students. The transcripts also should include the internship completion certificate. Accepted form of identification should also accompany with the transcripts, fees and application.

\section{Certificate of registration}

A registered pharmacist certificate (In a sealed and stamped envelope) is to be sent along with the application. This can be sent directly by the pharmacy board to the NABP or through a candidate along with the application or later depending upon on the practices of the Pharmacy Board of the respective country.

Journal of Young Pharmacists Vol 6 • Issue 3 • Jul-Sep 2014 


\section{Educational credential evaluation (ECE) evaluation ${ }^{6}$}

Educational credential evaluation report is required for all the foreign pharmacy graduates. This evaluation plays a crucial rule is deciding the eligibility status for FPGEE, so it is advised that the application for ECE is submitted along with/before submitting the FPGEE application. ECE (education evaluation application) is a private board which evaluates the transcripts and issues a report of the evaluation, which forms the base in decision making process for the board. Same set of documents is to be submitted to ECE along with the application and processing fee of 85\$. Any non-English documents should be translated into English prior to the submission.

\section{What next??}

After going through all the laborious process mentioned above, the board announces its decision in writing after scrutinizing all the summited documents in about 12 weeks. The time line depends on accurate the candidates submits his documents. Failure to comply with the boards requirements will cause a delay in announcing its decision. Once the decision is announced the candidate can go ahead and register for the test online. Eligibility for the test does not guarantee a visa, which is considered mandatory to enter the country. It is also appropriate to say that the fate of the candidate also lies in the hands of the visa issuing officer who gives the permission to enter the country for the test. In order to pass the test, the candidate has to achieve a minimum score of 75 or more. The total attempts for FPGEE is 5 failing, which the candidate can never apply again. After the test, it takes around 2 months for the results to come out and on passing the candidate can register for an internship in the state of his/her choice. The internship hours varies from state to state. Most of the states require $1500 \mathrm{~h}$. Once the intern hours are completed the NABP in co-ordination with the state pharmacy board issues an authorization to take NAPLEX and MPJE.

\section{Test of English as a foreign language (TOFEL) test $^{7}$}

TOFEL internet based test is mandatory for all the foreign graduates and should be taken only in the US. An overall minimum score is not required but the candidate is deemed eligible only if the candidate obtains the minimum required scores in the following areas:

- Speaking: 26

- Reading: 22

- Listening: 21

- Writing: 24
Once the test-taking is completed the candidate is required to forward the official score to the board. The cost-effective way to take the TOFEL test is to take it the same time when the candidate enters the US for FPGEE since NABP does not approve TOFEL test scores for the test taken outside the US.

\section{Current scenario}

As I am the principal author of this article, I am currently working as an intern in a retail pharmacy in Dallas Texas. It took me a while to find this intern position after passing my FPGEE and I found out two key reasons for the delay. The first reason is that, The U. S. has around 125 universities offering Pharm.D degrees with an average enrollment of more than 120 students. ${ }^{8}$ Right now they are producing enough number of pharmacists to meet their healthcare demand in hospitals and retail pharmacies. There unemployment for American Pharm.D in the states of New Jersey, New York, Pennsylvania, Connecticut and Maryland. Job opportunities are not that good in other 45 states also. The field in the US is saturated with all kinds of pharmacy graduates from the US and across the world.' The second reason is the visa status. The "Big Retail Chain" pharmacies like Walmart, Walgreens, CVS etc., and the hospitals are not inclined towards hiring a foreign graduate as an intern as they have to sponsor a work visa (Also known as H1 Visa) for the employee, which is cost and time consuming. Hence, the options especially for our Indian Pharm.D graduates are confined to small retail pharmacies mostly owned by Indians if and only if they are willing to sponsor for a work visa (H1). Eventually, it is up to an individual whether to go through all the above mentioned laborious process and take a chance in the US or opt for a career in India or any other country.

\section{CONCLUSION}

There is no alternative to the above laborious process if one plans their career in the US. Some people might think the process is expensive and laborious but others find it worthy. This article is intended for all the people who decides to take a shot and fulfill their dreams of settling down in the "Land of Opportunities." It's is only after FPGEE certification (FPGEEC) a foreign graduate is treated equal to an American graduate and the process that follows after is exactly the same for both. FPGEEC is the initial step that eventually leads to NAPLEX and MPJE which are the hurdles to be cleared to establish oneself as a registered pharmacist in the US of America. A graduate deemed eligible to sit for FPGEE by the board is automatically 
assumed eligible for NAPLEX and MPJE. As mentioned earlier, FPGEE eligibility is just a passport and an actual visa is required to enter the country lawfully without which the passport is rendered futile. One must also consider the current scenario and the opportunities available in the US for foreign graduates before commencing the above process.

\section{REFERENCES}

1. Evaluation Reports for the National Association of Boards of Pharmacy (NABP)/Foreign Pharmacy Graduate Examination Committee (FPGEC). Available from: https://www.ece.org/nabp. [Last accessed on 2014 Jun 02].

2. Pharmacy Council of India. Available from: http://www.pci.nic.in/. [Last accessed on 2014 Mar 20].
3. Ahmad A, Srikanth BA, Patel I. Indian Pharm.D: Should it be pursued? Arch Pharm Pract 2014;5:97-8.

4. National Association of Boards of Pharmacy. Available from: http://www. nabp.net/about. [Last accessed on 2014 Jun 02].

5. National Association of Boards of Pharmacy, FPGEE Application Bulletin. Available from: http://www.nabp.net/programs/examination/fpgec/ application-bulletin. [Last accessed on 2014 Jun 02].

6. Educational Credential Evaluators. Available from: https://www.ece.org/ nabp. [Last accessed on 2014 Jun 02].

7. National Association of Boards of Pharmacy, TOEFL-IBT. Available from: http://www.nabp.net/programs/examination/fpgec/toefl-ibt. [Last accessed on 2014 Jun 02].

8. Academic Pharmacy's Vital Statistics. Available from: http://www.aacp. org/about/pages/vitalstats.aspx. [Last accessed on 2014 Jun 02].

9. Local Jobs in NJ. Available from: http://www.jobs.nj.com/jobs/results/ keyword $/$ pharmacist? modifiedDate $=\% 5 \mathrm{BNOW} 28 \mathrm{DAYS}+\mathrm{TO}+\mathrm{NOW} \%$ 5 D\&radius $=0 \&$ rows $=20$. [Last accessed on 2014 Jun 02]. 